\title{
Employee Perceptions of Organisational Emotional Intelligence and Psychological Capital Amongst Public Servants in Uganda
}

\author{
Jolly Byarugaba Kabagabe \\ Makerere University \\ Drikus Kriek \\ Witswatersrand University
}

We developed and tested a model examining the association between organisational emotional intelligence and psychological capital in the workplace. Employing the organisational positivity argument, we proposed that organisational emotional intelligence be associated with higher order psychological capital. We tested our hypothesis using cross sectional data from employees from public organisations in Uganda. The study established that employee perceptions emotional intelligence organization organisations could be associated with employee psychological capital. organisational managers should develop organisational emotional intelligence which is manifested through job happiness, compensation satisfaction, supervisory leadership, organisational cohesiveness, responsiveness, work life stress management, diversity and anger management, and positive impression management creating a positive emotionally intelligent organisation to develop psychological capital for positive outcomes.

Keywords: organisational emotional intelligence (OEI), psychological capital (PsyCap), organisational sector, public servants, Uganda

\section{INTRODUCTION}

Today, psychological capital (PsyCap) is considered as a bottom line for individual and organisational performance (Avey, Reichard, Luthans, \& Mhatre, 2011, Muhammadi, Zahir, Ghourchian \& Jafari, 2015). PsyCap has been defined as the positive psychological development state of an individual characterized by having confidence (self-efficacy), optimism, hope and resilience to attain success (Luthans, 2002). A metaanalysis by Newman, Ucbasaran, Zhu, Hirst, (2014) which reviewed over 66 PsyCap studies, found a significant relationship between PsyCap and performance, attitudinal, behavior and well-being outcomes at individual level, team and organisational levels. An earlier meta-analysis by Avey, et al, (2011) of 51 independent samples involving 12,400 employees, supports that PsyCap is significant positive predictor of desired attitudes including job satisfaction, organisational commitment and psychological wellbeing and desired citizen behaviours with multiples measures of performance. Other recent studies have confirmed a relationship between PsyCap and other positive outcomes, commitment (Jain \& Kuma, 2017) organisational citizenship behavior (Pradhan, Jena and Bhattacharya, 2016; Lather and Kaur, 2015), work engagement (Simon and Buitendach, 2013) among others. Despite a few emerging studies on outcomes of PsyCap, few studies more studies are required to understand the correlates of PsyCap (Luthans and Morgan, 
2017, Avey, 2014). The contribution of this paper is to add to the body of knowledge by providing further evidence on the relationship between emotional intelligence and PsyCap in a developing economy.

Uganda is a developing country in East Africa. East Africa is composed of Uganda, Kenya, Tanzania, Rwanda and South Sudan. The public sector in Uganda is considered a huge employer, traditional with low pay, low productivity in some sectors funded by tax payer. Increasing economic performance depends in part on creating a more productive and efficient public sector. Uganda is one of the East African countries, with some of the developing economy challenges. The World Economic Forum (WEF) has been ranking the Ugandan's country labour productivity among the bottom 25 out of 144 countries over the last five years. In addition, the Global Competitiveness Report (Schwab, 2014) indicated that compared to other countries in the East African region, Uganda has the lowest labour productivity. In comparison, Ugandan employees have been criticised as having low work morale and low levels of productivity compared to the other East African countries. Some studies have claimed that Uganda's workforce is $28 \%$ and $86 \%$ less productive than the Tanzanian and Kenyan workforce respectively. There are still major performance and productivity challenges in Uganda (Byaya, 2017). The public sector is no exception to these challenges.

The public sector in Uganda is composed of government central ministries, local government, government departments and agencies. The Public service management reforms are captured in the PublicSector Reform Programme (PSRP) of 2005/06-2010/11, which sought to address several public-sector challenges in Uganda; skills gap and weak management, weak performance and accountability; inefficient and over-extended public organisations; a disabling work environment, poor pay and sustainable support for reform among political and technocratic leadership. Despite these PSRP initiatives, performance crises, incompetency, poor accountability and declining service standards have continued to bedevil Uganda's public service.

A body of research knowledge over the past decade emphasized evidence of the beneficial role of PsyCap in organisational setting (Valdez, King, \& Datu, 2016). PsyCap is linked to individual desired positive work outcomes and organisational effectiveness (Luthans \& Morgan, 2017, Waldez, et al, 2016; Avey, Reichard, Luthans \& Mhatre, 2011); a pre-requisite for individual and organisational success (Du Plessis \& Barkhuizen, 2011). However, few studies have examined predictors of psychological capital (Avey, 2014). This study makes a contribution by analysing if there is a positive significant association between emotional intelligence and psychological capital.

Further a few studies have emerged focusing on emotional intelligence and PsyCap at the individual level. For instance, study by Simsek and Aktas (2016) established that emotional intelligence explained 28 percent of the variance in PsyCap (Simsek \& Aktas, 2016, Meliao \& Monico, 2013). Though, have focused at individual level analysis, it is possible the perceptions of organisational level emotional intelligence could have an effect on psychological capital. Moreover, there is empirical evidence that there is a strong positive relationship between organisational climate and PsyCap (Singh, Happy, \& Kumar, 2015). Organisational emotional intelligence has sub constructs of a positive environment climate; thus this study hypothesized that:

$\boldsymbol{H}_{1}:$ Organisational emotional intelligence has a positive significant association with each dimension of PsyCap (self-efficacy, hope, optimism, resilience)

$\boldsymbol{H}_{2:}$ Organisational emotional intelligence has a positive significant association with the high order PsyCap.

Purpose: To analyse the association between organisational emotional intelligence and psychological capital among public servants in Uganda

\section{METHODOLOGY}

The section below will describe the methodology used in the study including research approach, measuring of instruments, research procedure, study participants, data analysis and interpretation. 


\section{Research Approach}

The study consisted of cross-sectional survey data from employees of various public sector organisations including ministries, agencies, government departments and local government. The data was analysed using quantitative inferential statistics using correlations, regression analysis.

\section{Measuring Instruments}

The study variables were assessed using previously validated instruments as described below and further validated for this study through and exploratory factor analysis.

\section{The Psychological Capital Questionnaire (PCQ)}

The 24-item PCQ to measure PsyCap (Luthans, Youssef and Avolio, 2007) was used. The PCQ has been used by other researchers and has demonstrated adequate psychometric properties in several other samples (Luthans, Avey, Avolio \& Peterson, 2010). After exploratory factor analysis the composite PsyCap also measured the subscale constructs self-efficacy (4 items) hope 4 items), optimism (3 items) and resilience (3 items). In this study sample, the PCQ demonstrated internal consistency reliability for the full scale with a Cronbach's Alpha of $\alpha=.877$. The Cronbach's Alpha for dimensions of PsyCap are selfefficacy, $\alpha=.756$; hope, $\alpha=.709$; resilience, $\alpha=.688$; and optimism, $\alpha=.647$. Although the value of the resilience and optimism is lower than the recommended cut of .7 by current researchers in literature; the alpha values are above the 0.6 recommended by Nunnally (1978). The overall PsyCap met the conditions for internal consistency of the 24 items. Further a confirmatory factor analysis (CFA) using maximum likelihood estimation (ML) indicated an acceptable model fit, with fit indices of C/MIN/DF $=2.2$, GFI $=.997, \mathrm{AGFI}=.984, \mathrm{NFI}=.993, \mathrm{CFI}=.996, \mathrm{TLI}=.988$, and $\mathrm{RMSEA}=.044$; confirmed an acceptable good measurement model fit for PsyCap using the criteria that ratio of the chi-square statistic to the degree of freedom ( $\mathrm{x}^{2} / \mathrm{df}$ should be 3 -to- 1$)$, CFI value $\geq .80$ and RMSEA $\leq 0.08$ as the goodness-of-fit tests (Benter, 2007; Field, 2009), were found acceptable for the measurement model of PsyCap.

\section{The Organisational Emotional Intelligence Questionnaire (OEI)}

The Stein (2005) scale of BOEI was used. The BOEI was validated by Stein in large samples from various organisations. It has been used by other researchers and has demonstrated adequate psychometric properties in several other samples (Pomraring, 2010). The composite OEI measures eight subscale dimensions: After exploratory factor analysis the following items were retained for further analysis: job happiness (4 items), compensation satisfaction ( 7 items), supervisory leadership (6 items) cohesiveness (9 items), responsiveness, work life balance ( 5 items), diversity management (11 items), positive impression (5 items). In this study the OEI composite full-scale model showed internal consistency of the items with a Cronbach alpha value of .925 for overall scale; with the Cronbach alpha of job happiness $(\alpha=.684)$ compensation satisfaction $(\alpha=.701)$, work life balance $(\alpha=.671)$, organisational cohesiveness $(\alpha=.785)$, supervisory leadership $(\alpha=.883)$, organisational responsiveness $(\alpha=.844)$ and positive impression $(\alpha=$ .691 ). These are considered acceptable levels of reliability of the instrument (Nunually, 1978). Further confirmatory factor analysis reported an acceptable OEI measurement model following the reported fit indices $\mathrm{C} / \mathrm{MIN} / \mathrm{DF}=5.0, \mathrm{GFI}=.972, \mathrm{AGFI}=.944, \mathrm{NFI}=.973, \mathrm{CFI}=.978, \mathrm{TLI}=.967$, and $\mathrm{RMSEA}=.077$ (Field, 2009).

\section{Research Participants}

The participants in the study were employed in different public sector organisations. The majority of participants in the study $154(23.3 \%)$ were from government authorities, $140(21 \%)$ from government ministries, 107 (16.0\%) from government agencies, 87 (13.0\%) from local government, 66 (9.9\%) from state enterprises, $54(8.1 \%)$ from training institutions, $48(7.2 \%)$ from commissions and 7 (1.1\%) from government boards. The participants were from different functional department; which included the majority $179(26.8 \%)$ of the participants from operations and administration departments, $140(21.0 \%)$ from human resource management departments, 94 (14.1\%) from finance and accounting, 57 (8.5\%) from procurement and logistics, 37 (5.5\%) from information technology management, 34 (5.1\%) from marketing 
and public relations, and $15(2.2 \%)$ from corporate affair; with a considerable number $142(21.0 \%)$ of participants from unspecified departments in the public sector. The majority of respondents were male, 402 (60.5), as against 266 (39.5) female respondents; with the majority (287) of the respondents were aged between 25 and 34 years (43.0\%), followed by 253 aged between 35 and 54 years (37.9\%), followed by 94 respondents below 25 years of age (16.0\%), while only 21 (3.1) were above 55 years of age. Many of the employees who participated in the study held qualifications higher than a bachelor's degree. The majority $297(44.5 \%)$ of participants held a bachelor's degree, $179(26.8 \%)$ held a master's degree; while 114 $(17.6 \%)$ did not hold any degree, and 78 (11.6) held other unspecified qualifications. The data indicates that the majority of employees who participated in the study had more than five years of public service experience. Of these, 195 (29.2\%) had 6 to10 years of public service experience; $156(23.4 \%)$ had 11 to 15 years; while $68(10.2 \%)$ had over 21 years' experience; $23(3.4 \%)$ with unspecified experience.

\section{Research Procedure}

The research procedure for the study involved inviting employees from various public sector organisations to participant voluntarily in the study by completing a consent form. Self-administered questionnaires were used, which were distributed to employees from various public sector organisations were approached for informed concert to participate in the study. Those who consented to participate were requested to fill in the questionnaires voluntarily. The participants were allowed to withdraw from the study at any time they choose to. The participant's confidentiality was protected by ensuring that no names were required on the questionnaire and the questionnaire was returned confidentially in a closed envelope. During the research, precautionary measures were taken to ensure participant's anonymity and confidentiality of data, ensuring conformity to research ethical values. The data were collected between September 2014 and January 2015, without time limit to answer the questionnaire. The questionnaires were returned within one month after distribution.

\section{Data Analysis}

The quantities survey data was analysed using SPSS version 20, Pearson correlation was used to test relationships, stepwise regression to test effect of organisational emotional intelligence, organisational category on psychological capital. In addition, a structural equation modelling was used to establish if there was a model fit between organisational emotional intelligence and psychological capital using data from the public sector in Uganda. The following are the reported results:

\section{RESULTS}

The correlation results are presented in the following table 1 . 


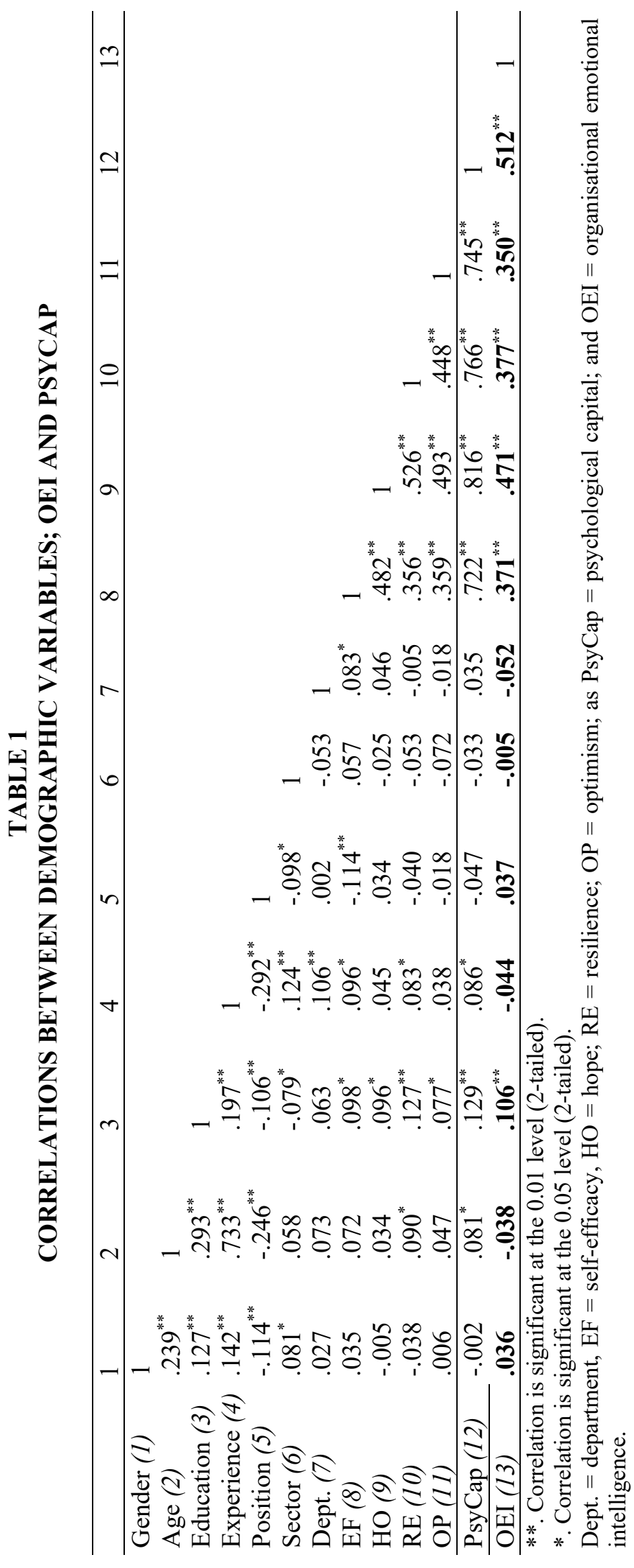


Table 1 presents the bivariate correlations between study variables. Results show that age $(\mathrm{r}=.081, \mathrm{p}$ $\leq .05)$, education $(\mathrm{r}=.129, \mathrm{p} \leq .01)$, and experience $(\mathrm{r}=.086, \mathrm{p} \leq .05)$ are positively related to PsyCap, however there is no significant relationship between gender $(\mathrm{r}=-.002$, ns) employee managerial position $(\mathrm{r}$ $=-.047, \mathrm{~ns})$, employee public service sector $(\mathrm{r}=-.033, \mathrm{~ns})$, employee functional department $(\mathrm{r}=.035, \mathrm{~ns})$. Further results indicate that OEI is related to PsyCap $(\mathrm{r}=.512, \mathrm{p} \leq .01)$ and its (PsyCap dimensions): selfefficacy $(\mathrm{r}=.371, \mathrm{p} \leq .01)$, hope $(\mathrm{r}=.471, \mathrm{p} \leq .01)$, optimism $(\mathrm{r}=.377, \mathrm{p} \leq .01)$, resilience $(\mathrm{r}=.350, \mathrm{p} \leq$ $.01)$. A regression analysis of the composite effect of organisational emotional intelligence on construct of psychological capital and higher order (combined constructs) PsyCap as reported in table 2. The findings are reported in Table 2:

\section{TABLE 2 \\ EFFECT OF OEI ON PSYCAP AND IT DIMENSIONS (EFFICACY, HOPE, RESILIENCE, OPTIMISM)}

\begin{tabular}{|c|c|c|c|c|c|}
\hline \multirow{3}{*}{ Variable } & \multicolumn{5}{|c|}{ Dependent variable } \\
\hline & Model1 & Model2 & Model3 & Model4 & Model5 \\
\hline & Self-efficacy & Hope & Resilience & Optimism & PsyCap \\
\hline Gender & -.008 & -.034 & -.081 & .017 & -.047 \\
\hline Age & -.002 & .012 & .070 & .036 & .040 \\
\hline Educ & .039 & .037 & .062 & .021 & .050 \\
\hline Exp & .069 & .062 & .049 & 0.37 & .071 \\
\hline Pos & -.094 & .049 & -.026 & .013 & -.033 \\
\hline Sect & .051 & -.018 & . -052 & .076 & -.035 \\
\hline Dept & $.096 * * *$ & .061 & .061 & .011 & .048 \\
\hline OEI & $379 * * *$ & $.473 * * *$ & $379 * * *$ & $351 * * *$ & $.517 * * *$ \\
\hline $\mathrm{R}$ & & & & & .560 \\
\hline $\mathrm{R}^{2}$ & & & & & .314 \\
\hline Adjusted $\mathrm{R}^{2}$ & & & & & .302 \\
\hline F change & & & & & 27.293 \\
\hline Sig & & & & & .000 \\
\hline
\end{tabular}

**. Correlation is significant at the 0.001 level (2-tailed).

**. Correlation is significant at the 0.01 level (2-tailed)

*. Correlation is significant at the 0.05 level (2-tailed).

In model 1: Self-efficacy dimension of PsyCap was set as the dependent variable, control variables (gender, age, education, experience employee position, public service sector and department as control variables; OEI was set as the independent variable to make a regression analysis. The co-efficient of the independent variable OEI is significant $(\beta=.379, \mathrm{p} \leq .001$, showing that OEI has a positive and significant effect on the self-efficacy dimension of PsyCap.

In model 2: Hope dimension of PsyCap was set as the dependent variable, control variables (gender, age, education, experience employee position, public service sector and department as control variables); OEI was set as the independent variable to make a regression analysis. The co-efficient of the independent variable OEI is significant $(\beta=.473, \mathrm{p} \leq .001$, showing that OEI has a positive and significant effect on hope dimension of PsyCap.

In model 3: Resilience dimension of PsyCap was set as the dependent variable, control variables (gender, age, education, experience employee position, public service sector and department as control variables); OEI was set as the independent variable to make a regression analysis. The co-efficient of the independent variable OEI is significant $(\beta=.379, \mathrm{p} \leq .001$, showing that OEI has a positive and significant effect on resilience dimension of PsyCap.

In model 4: Optimism dimension of PsyCap was set as the dependent variable, control variables (gender, age, education, experience employee position, public service sector and department as control 
variables); OEI was set as the independent variable to make a regression analysis. The co-efficient of the independent variable OEI is significant $(\beta=.351, \mathrm{p} \leq .001$, showing that OEI has a positive and effect on optimism dimension of PsyCap.

Finally, in model 5: PsyCap was set as the dependent variable, control variables (gender, age, education, experience employee position, public service sector and department as control variables); OEI was set as the independent variable to make a regression analysis. The co-efficient of the independent variable OEI is significant $(\beta=.517, \mathrm{p} \leq .001$, showing that OEI has a positive and significant effect on PsyCap. The Adjusted $\mathrm{R}^{2}$ is $.302 \mathrm{p} \leq .000$, suggesting that OEI could explain $30.2 \%$ of the variance in PsyCap.

In further validation of a model fit structural equation model using Amos 2.0 was used to establish a model fit between organisational emotional intelligence (OEI) and psychological capital (PsyCap). The model specified significant demographic characteristics including education of respondents, OEI and PsyCap. The final results after model re-specification, that removed insignificant demographics are presented in table 3:

TABLE 3

SEM SUMMARY STATISTICS FOR OEI AND PSYCAP

\begin{tabular}{|c|c|c|c|c|c|c|c|c|c|}
\hline \multirow{2}{*}{\multicolumn{2}{|c|}{$\begin{array}{l}\text { Variable } \\
\text { (OEI- } \\
\text { PCP) }\end{array}$}} & \multirow{3}{*}{$\begin{array}{l}X^{2} \\
169.33\end{array}$} & \multirow{2}{*}{$\begin{array}{l}\mathrm{DF} \\
52\end{array}$} & $\mathrm{X}^{2} / \mathrm{DF}$ & \multirow{2}{*}{\multicolumn{2}{|c|}{$\begin{array}{l}\mathrm{P} \\
.000\end{array}$}} & \multirow{2}{*}{$\frac{N F I}{952}$} & \multirow{2}{*}{$\begin{array}{c}\text { GFI } \\
.959\end{array}$} & \multirow{3}{*}{$\begin{array}{l}\text { AGFI } \\
.939 \\
\text { B } \\
\end{array}$} \\
\hline & & & & 3.25 & & & & & \\
\hline & & & \multicolumn{3}{|c|}{ Standardized Estimate } & S.E. & C.R. & $\mathrm{P}$ & \\
\hline PCP & $<---$ & OEI & .374 & & & .034 & 11.060 & $* * *$ & .614 \\
\hline PCP & $<---$ & EDU & .049 & & & .020 & 2.413 & .016 & .084 \\
\hline PI_ & $<---$ & OEI & 1.000 & & & & & & .783 \\
\hline OR & $<---$ & OEI & .983 & & & .040 & 24.834 & $* * *$ & .871 \\
\hline DI & $<---$ & OEI & .496 & & & .040 & 12.501 & $* * *$ & .484 \\
\hline SL & $<---$ & OEI & .963 & & & .043 & 22.325 & $* * *$ & .800 \\
\hline $\mathrm{OC}$ & $<---$ & OEI & .984 & & & .042 & 23.320 & $* * *$ & .828 \\
\hline $\mathrm{CS}$ & $<---$ & OEI & .750 & & & .046 & 16.162 & $* * *$ & .610 \\
\hline $\mathrm{JH}$ & $<---$ & OEI & .871 & & & .040 & 21.729 & $* * *$ & .783 \\
\hline $\mathrm{EF}$ & $<---$ & $\mathrm{PCP}$ & 1.000 & & & & & & .589 \\
\hline $\mathrm{HO}$ & $<---$ & PCP & 1.267 & & & .093 & 13.640 & $* * *$ & .795 \\
\hline $\mathrm{RE}$ & $<---$ & PCP & 1.089 & & & .087 & 12.452 & $* * *$ & .656 \\
\hline $\mathrm{OP}$ & $<---$ & PCP & 1.010 & & & .083 & 12.108 & $* * *$ & .628 \\
\hline
\end{tabular}

Note: $\mathrm{PCP}=$ psychological capital, OEI = organisatiional emotional intelligence; PI = positive impression; OR = organisational responsiveness; DI = diversity management; $\mathrm{SL}=$ supervisory leadership; OC = organisational cohesiveness; $\mathrm{CS}=$ compensation satisfaction; $\mathrm{JH}=$ job happiness; $\mathrm{EF}=$ self-efficacy; $\mathrm{HO}=$ hope; $\mathrm{RE}=$ resilience; $\mathrm{OP}=$ optimism

Structural equation model (SEM) for organisational emotional intelligence and psychological capital (OEI-PCP) analysis is described (Table 3). The analysis generated a chi-square of 169.33 at p-value .000 significant; suggesting a poor model fit. However, other fitting indices including/MIN/DF $=3.25$, GFI $=.959, \mathrm{AGFI}=.939, \mathrm{NFI}=952, \mathrm{CFI}=966, \mathrm{TLI}=9557$, and $\mathrm{RMSEA}=.058$ (below 0.08 is acceptable); thus, supported an acceptable model fit (Benter, 2007; Field, 2009). Path analysis reported significant path coefficients for organisational emotional intelligence $(\beta=.614$; $C R>1.96, p=.000)$. In line with Field (2009); based on AGFI (>.90) and RMSEA ( $\leq .08)$; SEM reported an acceptable model fit for organisational emotional intelligence and psychological capital, thus supporting a model for education, OEI-PsyCap among employees in the public sector as represented in figure 1. The findings are discussed in the next section. 


\section{FIGURE 1 \\ SEM MODEL FOR ORGANISATIONAL EMOTIONAL INTELLIGENCE AND PSYCHOLOGICAL CAPITAL}

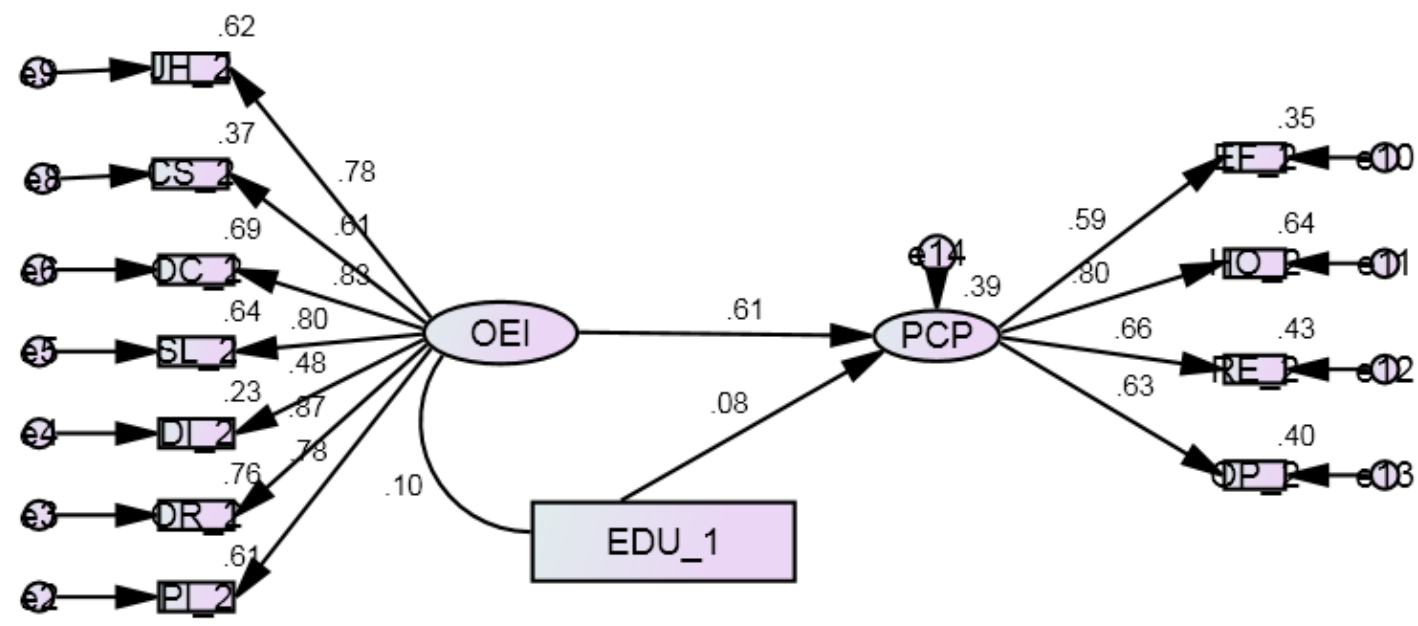

$$
\begin{aligned}
& \text { Chi-Square }(\mathrm{CMIN})=169.332 \\
& \text { Degree of Freedom }(\mathrm{DF})=53 \\
& \text { Probability }(p)=.000 \\
& \text { Ratio of Chi-Square to Degree of Freedom (CMIN/DF) }=3.256 \\
& \mathrm{RMR}=.036 \\
& \text { Goodness of Fit }(\mathrm{GFI})=.959 \\
& \text { Adjusted Goodness of Fit }(\mathrm{AGFI})=.939 \\
& \text { Tucker Lewis Index }(\mathrm{TLI})=.957 \\
& \text { Normed Fit Index }(\mathrm{NFI})=.950 \\
& \text { Comparative Fit Index }(\mathrm{CFI})=.966 \\
& \text { Root Mean Square Error of Approximation (RMSEA) }=.058 \\
& \text { Average Variance Explained }(\mathrm{AVE})=.560 \\
& \text { Composite Reliability }(\mathrm{CR})=.737 \\
& \mathrm{CS}=\text { Compensation Satisfaction } \\
& \mathrm{OC}=\text { Organisational Cohesiveness } \\
& \mathrm{SL}=\text { Supervisory Leadership } \\
& \mathrm{DI}=\text { Diversity and Anger Management } \\
& \mathrm{OR}=\text { Organisational Responsiveness } \\
& \mathrm{PI}=\text { Organisational Positive Impression } \\
& \mathrm{PCP}=\text { Psychological Capital } \\
& \mathrm{EF}=\text { Self Efficacy } \\
& \mathrm{HO}=\text {-Hope } \\
& \text { RE }=\text { Resilience } \\
& \mathrm{OP}=\text {-Optimism } \\
& \text { PCP = Psychological Capital }
\end{aligned}
$$

\section{DISCUSSION AND CONCLUSION}

The purpose of this study was to analyse the role of organisational category in the relationship between organisational emotional intelligence and PsyCap. Organisational emotional intelligence (OEI) and psychological capital (PsyCap) are relatively new phenomena with positive outcomes in work life (Simsek and Aktas, 2016). The effect of organisational emotional intelligence is on psychological capital was investigated in a sample of public servants. Organisational emotional intelligence was established to influence the sub factors of psychological capital (self-efficacy, hope, resilience, optimism) and PsyCap in a regression model of OEI explaining $30.2 \%$ of PsyCap. A structural equation model confirmed a model 
fit of education, OEI and PsyCap. This means that employees who perceive their organisations to be emotionally intelligent could report high levels of PsyCap by being confident in performing their tasks, optimistic in succeeding now and in the future, believing in accomplishing the set goals, and bearing up (resilient) in the face of challenges or opportunities (Mohammadi, Zahar, Ghourchian \& Jafari, 2015).

The findings of this study is consistent with previous study by Singh, Happy, \& Kumar (2015); which provided support that nurturing organisational climate is required in order to ensure higher levels of PsyCap. People are being the biggest asset for any organisatiion, and so there should be a good climate in the organization so that the employees can enjoy their work and help attaining the goal of the organisations. For better organisational climate of employees the supervisor should maintain good relationship with the employees and should encourage them and when they have problems, they should be provided the required help to solve the problems. Supervisors should listen to their employees' suggestions about work. Opportunities for training should be offered by the organisations. If the employees need help because of a heavy workload, they should be provided the necessary means (Singh, Happy, \& Kumar, 2015).

The study makes a contribution by responding to a call by PsyCap researchers to investigate more correlates of PsyCap (Luthans \& Morgan, 2017). This study provides analysis of the association between organisational level emotional intelligence and employee psychological capital PsyCap. The study established significant positive effect of organisational emotional intelligence and PsyCap.

These findings of this study indicate that organisational emotional intelligence plays an important role in facilitating PsyCap. Thus, an organisations's ability to efficiently and effectively cope with change, accomplish its goals, while at the same time being responsible, accountable and responsive to its employees is positively associated to PsyCap public sector organization. PsyCap would be demonstrated through its four characteristic elements of having confidence in challenging work and trying to complete it, treating the present and the future optimistically, facing the future by setting goals and taking careful steps to sustain the goals and in situations of challenges, frustration or even opportunities, persevering until success is attained across all categories of the public sector organisations (Luthans, et al, 2007). Organisational emotional intelligence could be displayed by the organization providing a work environment that create job happiness; which a feeling of wellbeing and fulfillment with workplace satisfaction and enjoyment; compensation satisfaction is satisfaction with one's pay, bonuses, and benefit; work-life stress management including work-life balance, employee stability and stress management; organisational cohesiveness that covers the ability of co-workers to work in cohesive teams and get along well with team members, supervisory leadership satisfaction and with others' trustworthiness and managing relationships; diversity and anger management including openness to diversity; frustration and anger controlled work environment; organisational responsiveness that meets the training needs of employees, encourages innovation, promotes optimistic attitudes and integrity, deals with difficult issues, demonstrates courage and adaptability, promotes a trust environment, adaptability, with a positive top management leadership; and positive impression management that allows organisational members to freely promote a positive image of the organisation (Stein, 2005).

\section{Practical Implications}

Organisations can create competitive advantage by developing and managing PsyCap among its employees (Luthans \& Morgan, 2017). The study advances knowledge establishing that organisational emotional intelligence could predict employee psychological capital. Understanding more associates of psychological capital offers additional opportunity to organisational leaders to find supplementary ways to increase employee peceptions of organisational emotional intelligence perceptions that could enhance employee psychological capital for employee positive outcomes. Some of the positive outcomes of psychological capital have been established to include including satisfaction, engagement, citizenship behavior, productivity (Luthans and Morgan, 2017). In line, the authors recommend organisations should design policies that create job happiness, compensation satisfaction, manage work and life stress, promote team's cohesiveness; promote organisational responsiveness, and positive organisational impression. (Stein, 2005). Organisational managers/leaders should enhance PsyCap and its four positive capabilities 
(self-efficacy, hope, resilience, optimism) using organisational resources such as organisational emotional intelligence.

\section{Limitations and Recommendations}

The key limitation of this study is its cross-sectional design nature that used convenience sampling of employees in the public sector. This limits the inference of causal effects between organisational emotional intelligence and PsyCap. Thus, further studies using experimental or longitudinal analysis would be required to confirm the direction of causal relationships. The study only analysed the organisatiional emotional intelligence and PsyCap in the context of public organisations.

In addition, the data collected for both independent and dependent variables was collected from the same respondent, which could lead to overstated relationships (Podsakoff, MacKenzie, Lee \& Podskoff, 2003), however to reduce this common source bias effect; data on the independent and dependent variable were collected at separate times. The questionnaire on the independent variable was distributed to those who filled questionnaire on dependent variables and willing to continue with the study only.

\section{Suggestions for Future Research}

The study focused on perceptions on perceptions of organisational emotional intelligence and psychological capital among employees in public sector organisations. Further research may analyse the predictive potential of each dimension of organisational emotional intelligence on psychological capital to create additional knowledge on key OEI dimensions that may positively affect PsyCap. Further research in the area of OEI and PsyCap may employee longitudinal studies to observe study variables over a reasonable time to understand the causal directions of these study variables. The study used a tool developed by a practitioner (Stein, 2005). Though, the measurement tool for organisational emotional intelligence has been used by other academic researchers (Pomraning, 2010), tested for validity and reliability; more studies will be required to validate the measurement tool. Other researchers could use other measurement tools developed by other academic scholars like Giorgi (2009) to measure organisational emotional intelligence. Additional knowledge would inform better organisational leaders to enhance PsyCap for organisational success. In addition, this study focused on the private sector; further comparative analysis studies in a variety of organisations is recommended to understand moderators in PsyCap studies (Luthans and Morgan, 2017).

\section{Conclusion}

The study explored the role on the emerging theory of organisational emotional intelligence on another area of current interest for researchers PsyCap in the public sector organisational setting (Newman, 2010) where such studies were limited. The theoretical foundation was positive organisational behavior (POB), the positive organisational resources in the form of OEI were measured. The study adds to a growing body of knowledge in organisational emotional intelligence and PsyCap theory. The study makes original contribution to knowledge by analysing perceptions of organisational emotional intelligence of employees at organisational level. Previous researchers have focused on emotional intelligence at the individual level. 


\section{REFERENCES}

Auditor General Report. (2015).

Avey, J.B. (2014). The left side of psychological capital: New evidence on the Antecedents of PsyCap. Journal of Leadership and Organisations Studies, 21(2), 141-149.

Avey, J.B., Reichard, R., Luthans, F., \& Mhatre, K. (2011). Meta-analysis of the impact of psychological capital on employee attitudes, behaviours and performance. Human Resource Development Quarterly, 22(2), 127-152.

Berman, E.M., \& West, J.P. (2008). Managing emotional intelligence in US cities: A study of social skills among public managers. Public Administration Review, 68(4), 742-758.

Du Plessis, Y., \& Barkhuizen, N. (2011). Psychological capital: A requisite for organisational performance in South Africa. South African Journal of Economics and Management Sciences, 15(1), 16-31.

Effective States and Inclusive Development (ESID). (2016, October). ESID Briefing No.23. Public Sector Reform Programmes (PSRP) in Uganda: Behind the façade. Retrieved from www.effective states-org.

Field, A. (2009). Discovering Statistics, Using SPSS (Third ed.). Thousand Oaks, CA: Sage.

Giorgi, G. (2013). Organisational emotional intelligence: Development of a model. International Journal of Organisational Analysis, 21(1), 4-18.

Goleman, D. (1995). Emotional Intelligence. New York: Bantam Books.

Hair, J.H., Jr., Black, W.C., Babin, B.J., \& Anderson, R.E. (2010). Multivariate Data Analysis (Seventh ed.). Upper Saddle River, NJ: Prentice Hall.

Inspector of Government Report. (2017).

International Transparency. (2017). Corruption Perception Index Report, 2017. Retrieved from http:www.transparency.org/policy research/survey indices/cpi/2017/results.

Jain, S., \& Kuma, S. (2017). Examining organizational commitment and psychological capital in Indian Bank Employees. Journal of Humanities and Social Sciences (IOSR-JHSS), 22(6), 14-22.

Luthans, F., \& Morgan, C.M. (2017). Psychological Capital: An evidence-based positive approach. Annual Review of Organisational Psychology and Organisational Behavior, 4(17), 17-28.

Luthans, F., \& Youssef, C.M. (2007). Emerging positive organizational behavior. Journal of Management, 33, 321-349.

Luthans, F., Avey, J.B., \& Peterson, S. (2010). The development and resulting performance impact of psychological capital. Human Resource Development Quarterly, 21(1), 41-67.

Luthans, F., Avey, J.B., Avolio, B.J., \& Peterson, S.J. (2010). The development and resulting performance impact of positive psychological capital. Human Resource Development Quarterly, 21, 41-67.

Luthans, F., Luthans, K.W.W., \& Luthans, B.C. (2004). Positive psychology: Beyond human and social. Business Horizons, 47(1), 45-50.

Luthans, F., Norman, S.M., Avolio, B.J., \& Avey, J.B. (2008). The mediating role of psychological capital in the supportive organizational climate-employee performance relationship. Journal of Organisational Behavior, 29(2), 219-238

Luthans, F., Youssef, C.M., \& Avolio, B.J. (2007). Psychological capital management: Measurement and relationship with performance and satisfaction. Organisational Dynamics, 33(2), 143-160.

Malik, S.Z., \& Masood, S. (2015). Emotional intelligence and resistance: Mediating role of psychological capital in the telecommunication sector of Pakistan. Pakistan Journal of Commerce and Social Science, 9(2), 485-503.

Mellao, N., \& Monico, L.S.M. (2013). The relationship between emotional intelligence and psychological capital. International Journal of Development and Educational Psychology, 2(1), 545-550.

Mohammadi, S.M., Zahar, A.T., Ghourchian N.G, \& Jafari, P. (2015). Surveying the effect of emotional intelligence and meta-cognitive on psychological capital of high school teachers in Boushehr Province. American Journal of Educational Research, 3(10), 1267-1269

Ndegwa. (2011). Decentralization Report on Africa. 
Nunnally, J.C., \& Bernstein, I.H. (1994). Psychometric Theory (Third ed.). New York: McGraw-Hill.

Podsakoff, P.M., MacKenzie, S.M., Lee, J., \& Podsakoff, N.P. (2003). Common methods variance in behavioural research: A critical review and recommended remedies. Journal of Applied Psychology, 88, 879-903.

Pomraning, C.D. (2010). Organisational emotional intelligence and trust. Doctoral Dissertation, Walden University.

Pradhan, R.K., Jena, L.K., \& Bhattacharya, P. (2016). Impact of psychological capital or organizational citizenship behavior: Moderating role of emotional intelligence. Cogent Business and Management. West Bengel, India.

Simons, J.C., \& Muitendach, J.H. (2013). Psychological capital, work engangement and organisational commitment among work engagement and organisational commitment amongst call centre employees in South Africa. SA Journal of Industrial Psychology/SA, 39(2), 1-12.

Simsek, E., \& Aktas, H. (2016). Is psychological capital a form of emotional intelligence? A research on University students. International Conference on Contemporary Issues in Education, 27-29 May, Zagreb -Croatia.

Singh, M., Paul, H., \& Kumar, S. (2015). Positive organisational climate, psychological capital and locus of control.

Stein, S.J. (2005). Benchmark of Organisational Emotional Intelligence, (BOEI), Technical Manual. Multi-Health Systems Inc.

Youssef, C.M., \& Luthans, F. (2007). Positive organisational behavior in the workplace: The impact of hope, optimism and resiliency. Journal of Management, 33, 774-800. 